\title{
Solar Orientation Measurement Systems with Integrated Solar Cells
}

\author{
Che-Ming Chiang ${ }^{1}$, Chia-Yen Lee ${ }^{2}$, Wen-Jen Hwang ${ }^{2}$ and Po-Cheng Chou ${ }^{3, *}$
}

\author{
${ }^{I}$ Department of Architecture, National Cheng Kung University, Tainan, Taiwan; ${ }^{2}$ Department of Materials Engineering, \\ National Pingtung University, Pingtung, Taiwan; ${ }^{3}$ Department of Interior Design, Shu-Te University, Kaohisung \\ County, Taiwan
}

\begin{abstract}
This paper presents a novel solar orientation measurement system based on solar cells. A methodology for calculating the solar orientation is developed in which the time and latitude angles of the sun are determined from the measured output voltages of inclined solar cells. Three types of measurement system are considered, namely a single cell type, a double cell type, and a quadrantal cell type. The relationship between the measured output voltages of the solar cells and the solar position is fully explored and documented for each measurement system. In the quadrantal measurement system, a variation in the time angle or latitude angle of the sun generates a corresponding change in the comparative output voltages of the East-West (E-W) or South-North (S-N) solar cells, respectively. By inclining the solar cells at an angle of 45 degrees, it is found that the comparative voltage ratio is sufficiently large that the time and latitude angles can be accurately predicted. The proposed measurement system provides a valuable contribution to the on-going development of tracking systems in the solar energy technology field.
\end{abstract}

Keywords: Solar cell, solar collector, solar orientation.

\section{INTRODUCTION}

Solar energy systems have emerged as a feasible source of renewable energy over the recent decades. Efficient solar collectors have been developed capable of collecting incident solar radiation and converting it into electrical power or thermal energy. The solar energy absorbed by these collectors can be increased by their integration with solar tracking systems which compute the direction of the solar vector based on location and time [1]. Using such tracking systems, the effectiveness of the solar collectors can be enhanced by ensuring that they are always oriented toward the sun [2-13]

Solar orientation measurement is an essential task in the solar energy field. Many previous studies have addressed the application of solar collectors in the development of solar energy technologies [14-18]. The use of automatic regulation systems for solar collectors has been proposed as a means of improving their solar radiation absorption capabilities. Experimental studies have been performed to investigate the performance of various types of solar tracking system, including passive systems [19] and active systems [20, 21]. McCluney proposed a passive optical solar tracking system consisting of a convex reflective sphere and a collimating lens designed to produce a collimated beam of solar radiation whose direction of propagation remained virtually constant over the daylight hours [19]. Semma and Imamura presented a microprocessor-based system capable of accurately tracking the sun for photovoltaic concentrator systems [20]. Using a two-axis equatorial mount and a microprocessor controller, Al-Naima and Yaghobian constructed a solar

\footnotetext{
*Address correspondence to this author at the Department of Interior Design, Shu-Te University, Kaohisung County, Taiwan; Tel: +886-7-6158000 ext. 3510; Fax: +886-7-6158000 ext. 3599; E-mail: paul@mail.stu.edu.tw
}

tracking system and demonstrated that it provided a better tracking performance than conventional one- axis controllers [21].

In the past two decades, closed-loop systems based on photosensors have emerged as the method of choice for controlling solar tracking systems. In such systems, the photosensors discriminate the sun's position and send electrical signals proportional to the error to the controller. The controller processes the electrical signals and then issues appropriate motor actuation instructions to drive the tracking system such that the error falls to zero. Many researchers have employed the Maximum Power Point Tracking (MPPT) principle for the construction and design of solar tracking systems [22-34]. Maish proposed the use of closed-loop control algorithms with a self-alignment routine and a selfadjusting motor actuation time to track the sun with a $\pm 0.1^{\circ}$ pointing accuracy [22]. Enslin investigated the relationship between the maximum power point and the input source tracked the maximum power point to the input source under varying input and output parameters, and developed a solar energy system with optimized power point tracking capabilities [23]. Kalogirou proposed a sun tracking system comprising three photosensors and three closed-loop control systems [24]. The tracking mechanism using multiple control systems was shown to have a tracking accuracy of between $0.05^{\circ}$ and $0.2^{\circ}$. To simplify the control logic, a multiple tracking measurement system with just two control loops was presented [25]. A tracking method with discrete time control was also presented to track the maximum power points of solar irradiation [27]. Helwa et al. compared different sun tracking systems equipped with closed-loop control algorithms and found that two-axis trackers achieved a better performance than vertical-axis or tilted-axis systems [28]. Kim et al. proposed an MPPT control algorithm for a photovoltaic power system subject to rapidly changing solar radiation by insert- 
ing test input signals in the control input [29]. Recently, Jiang and Cao used a four-quadrant photoelectric sensor to track the sun [32]. When the sun's rays and the tracking system sensor were mutually aligned, the photocurrents produced by the rays in each quadrant were equal. It was shown that the four-quadrant photoelectric sensor was capable of tracking the sun automatically. Aiuchi et al. also presented the use of a sun tracking photosensor for solar thermal concentration systems. In their design, two solar cells were placed side by side at the bottom of a box containing an aperture. When the solar radiation passed through the aperture, the solar cells were partially illuminated, and an electric current proportional to the illuminated area was generated at each cell. The direction of the reflected solar radiation was maintained as a constant by controlling the angle of the reflection mirror such that the two currents remained equal [34]. Various researchers have proposed the use of numerical optimization schemes for developing accurate solar tracking systems, including neural networks [35], fuzzy logic algorithms [36], and adaptive neuro-fuzzy control schemes [37].

In the last half-decade, various open-loop control systems have been proposed for predicting the solar orientation [1, 38-40]. Blanco-Muriel et al. proposed a solar concentrator tracking system which utilized open-loop controllers to compute the direction of the solar vector based on the system location and local time using a low-cost and modern programmable logic controller (PLC) [1]. Beshears et al. incorporated the date, latitude, longitude, and time zone into the PLC programming to improve the tracking system performance [38]. Recently, Georgiev et al. mounted three pryheliometers within a solar orientation measurement system and used the output signals from these devices to calculate the solar position [40]. Although the system demonstrated an autonomous measurement capability, it was rather bulky for practical use.

A review of the related literature identifies many different forms of solar sensor, including brightness sensors [41], artificial vision techniques, and CCD devices [9]. Measured solar energy values can be used to compute the absorbed solar energy as a function of the time of day [42]. Of particular interest is the two-axis analog device, which measures the solar position relative to its optical axis based on the signal obtained in a quadrant silicon detector [43]. However, although this device is attractive since it provides highly precise solar orientation measurements, its structure is rather complicated. Therefore, the present study develops a novel and more straightforward solar orientation measurement system based on an arrangement of four inclined solar cells. Under this arrangement, a methodology is developed to calculate the time and latitude angles of the sun based on the comparative output voltages of the East-West (E-W) and South-North (S-N) solar cells, respectively.

Generic algorithms have been applied to climate data to determine the optimum installation angle of a solar collector in different locations in Taiwan [44]. The optimum monthly and annual installation angles were obtained from computer simulations. Although sufficient installation information for solar collectors was provided, the solar orientation measurement was not instantaneous. Furthermore, the solar collectors were not integrated with a tracking system. The current study develops a methodology for solar orientation measurement based on the use of solar cells and direct solar irradiation geometry models. Three different sun sensor configurations are considered, namely single cell, double cell, and quadrantal cell. The characteristics of each sun sensor configuration are investigated and the correlation between the light source and the output voltages calibrated. It is shown that the time angle (i.e. the solar elevation angle) and the solar latitude angle (i.e. the solar azimuth angle) can be accurately estimated from the comparative output voltage signals of the back-to-back Eastern/Western solar cells and the Southern/Northern solar cells, respectively, in the quadrantal cell configuration.

\section{SENSOR DESIGN AND METHODOLOGY}

This study employs solar cells in various configurations to measure the time and latitude angles of the sun. In each configuration, the solar cells are connected to a personal computer to record and analyze the obtained measurement data. In solar cell systems, the photo-induced current, or the so-called generation current, is proportional to the number of photons collected on the surface area of the collector. The objective of this study is to relate changes in the measured output of the solar cells to changes in the elevation and azimuth of a light source (representing the sun) by means of an analyzer. The position of the light source is adjusted to reflect the solar position at different times of day and different latitudes. The irradiation absorbency of the solar cells differs at different incident angles of the irradiating light, and hence as the position of the light source is moved, the output voltage of the solar cells changes accordingly. In this study, the time angle, $\theta$, is defined as the angle between the incident ray and the horizontal plane, while the latitude angle, $\varphi$, is the angle between the incident ray and the eastern direction. Many studies have presented solar irradiation geometry models for solar devices [1, 6, 42, 44-48]. The present study uses a rectangular coordinate system to model the geometrical relationships between the sun and the sun sensors (Fig. 1). To simplify the problem, the plane equipped with the sun sensors is assumed to be horizontal. The latitude plane is bounded by the latitude of the solar position as the season changes. As time passes during the course of the day, the time plane sweeps the hemisphere from east to west. The intersection line of the latitude and time planes represents the trajectory of the incident ray from the sun. The latitude and time angles of the instantaneous location of the sun can be established by geometrical analysis.

In order to compare the performance of solar orientation measurement systems based on different solar cell configurations, this study developed three types of measurement system, namely single cell, double cell and quadrantal cell. An incandescent lamp (SC5848, HOMES, Taiwan) was used to simulate the sun. The wavelength of the irradiating light was 400-780 nm, which resembles that of solar light. In the single cell measurement system, a solar cell was laid in the horizontal plane and connected to a voltage meter which recorded the voltage change as the elevation angle of the light source was adjusted (Fig. 2). In the double cell system, two solar cells were inclined vertically and rested against one another. The comparative output voltage of the two cells was then measured at different solar orientations (Fig. 3). Finally, 


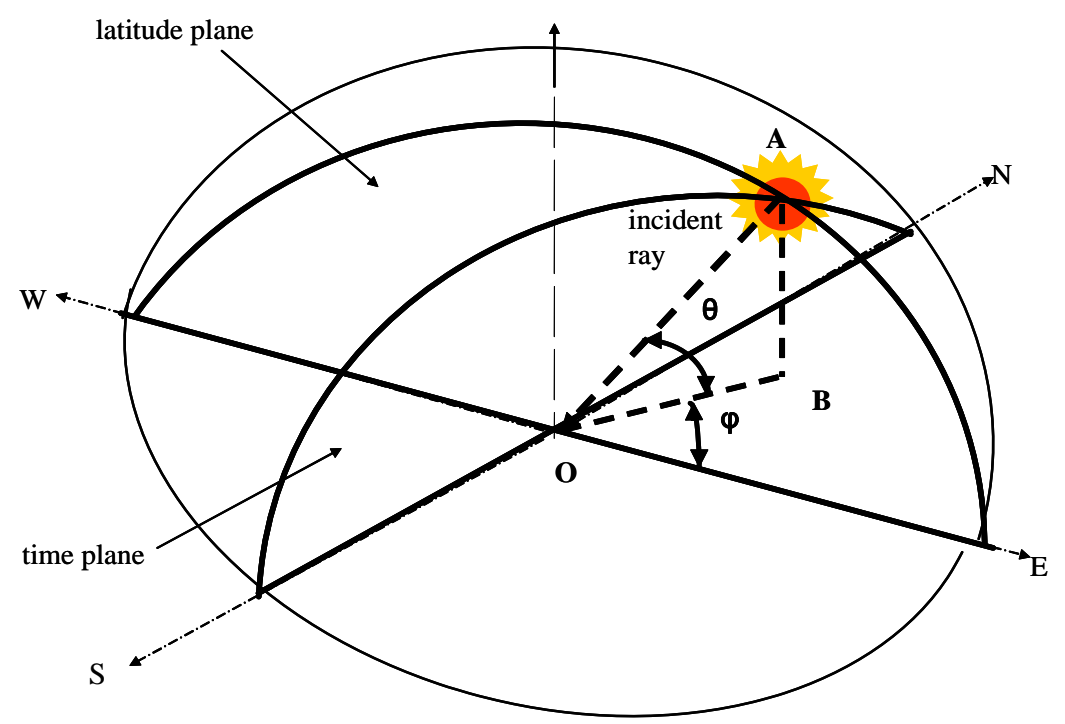

Fig. (1). Geometry of direct sunlight irradiation on sun sensors.

in the quadrantal measurement system, two sets of back-toback solar cells were integrated (Fig. 4). In this configuration, the time plane was defined by Sensors E and W, while the latitude plane was given by Sensors S and N. The comparative output voltages of the E-W and S-N sensors were measured and output to a personal computer, which then calculated the time and latitude angles of the solar incident ray.

\section{EXPERIMENTAL RESULTS}

The performance of the three solar orientation measurement systems was systematically examined. The characterization of the solar sensors was carried out in a dark room $(\mathrm{L}$ x W x H=3.5 m x $3.5 \mathrm{~m}$ x $2.5 \mathrm{~m}$ ). A voltage meter (3136A, Escort, Taiwan) was used to record the output signal response to changes in the position of the light source. The distance between the light source and the sun sensors was maintained at a constant $140 \mathrm{~cm}$ since the change in the distance between the sun and the Earth during the course of the day is negligible compared to the actual distance separating them. The measured data were recorded and processed in a personal computer.

\subsection{Single Cell Measurement System}

Fig. (2) presents a schematic illustration of the single cell measurement system. Fig. (5) shows the variation in the output voltage for different illumination powers as the elevation angle (representing the solar angle) was increased gradually from $-45^{\circ}$ to $90^{\circ}$. It can be seen that the output voltage increases gradually as the elevation angle is initially increased. However, when the elevation angle increases from approximately $-5^{\circ}$ to $0^{\circ}$, the voltage increases abruptly. As the eleva-

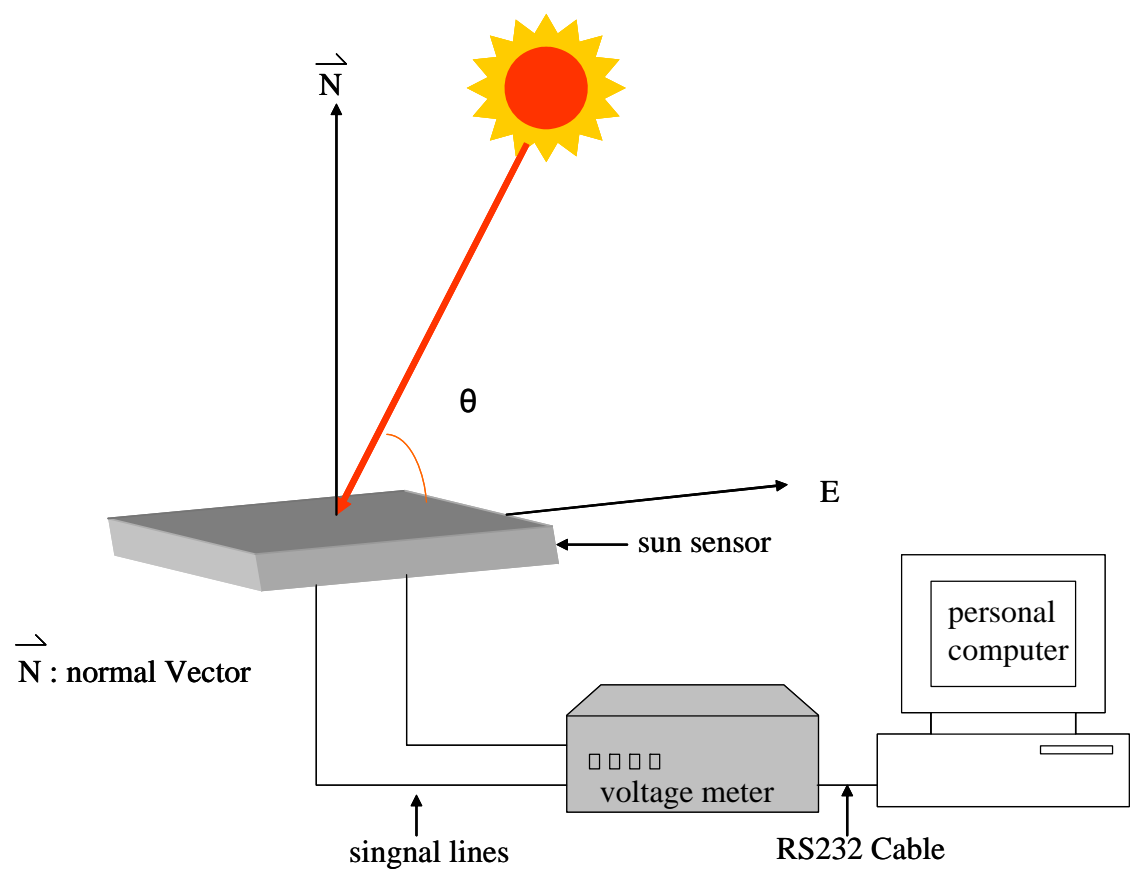

Fig. (2). Schematic representation of single cell measurement system. 


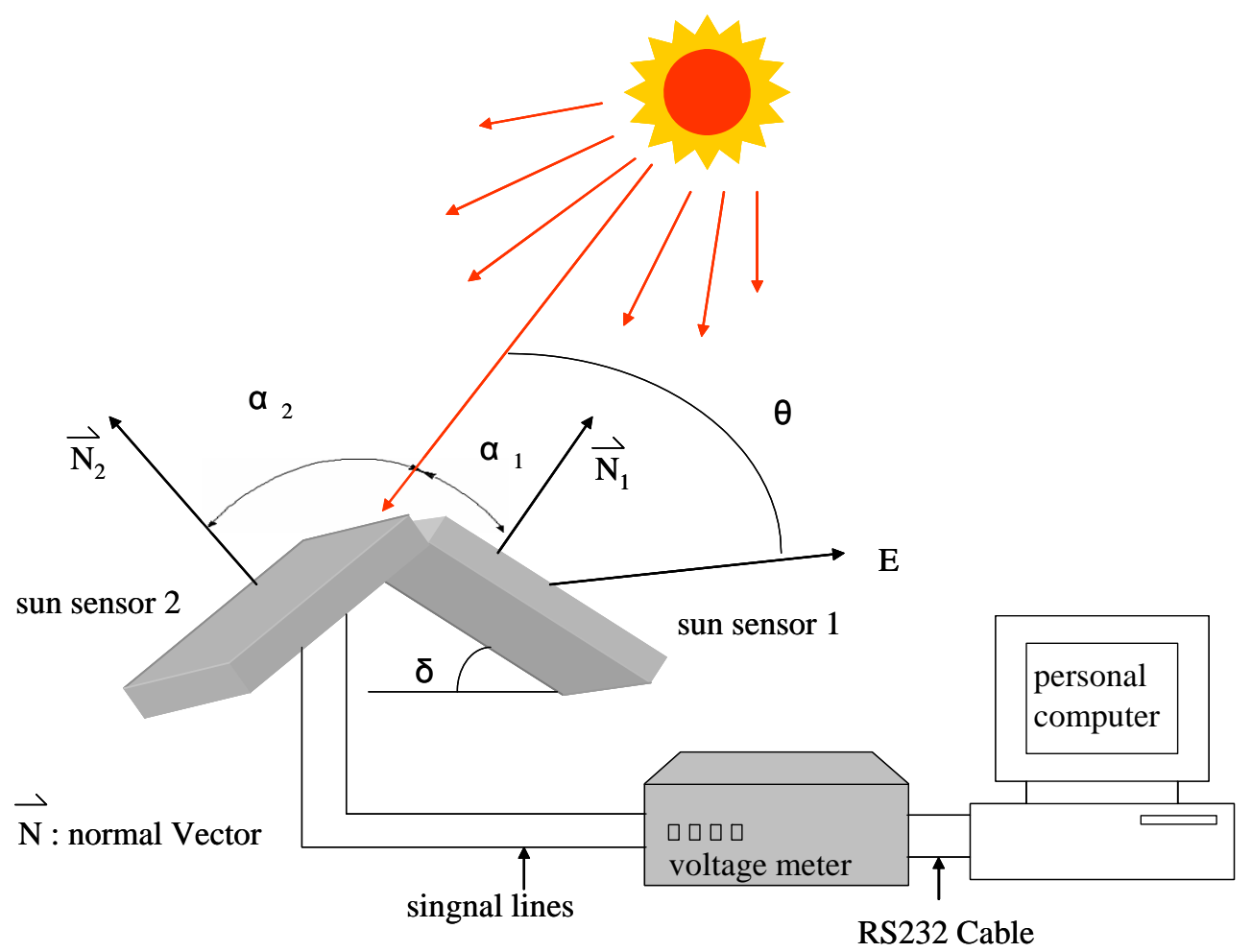

Fig. (3). Schematic representation of double cell measurement system.

tion angle is further increased towards $90^{\circ}$, the voltage continues to increase gradually and linearly. It can be seen that the output voltage increases as the power of the light source increases. Additionally, it is observed that the measured curve associated with an illumination power of $250 \mathrm{~W}$ has a better linearity. The output voltage increases linearly in the ranges of $-45^{\circ}$ to $-5^{\circ}$ and $0^{\circ}$ to $75^{\circ}$ for this particular illumination source, but becomes saturated when the elevation angle exceeds $75^{\circ}$. This implies that the single cell measurement system is unsuitable for use at high solar elevation angles such as those observed at noon.

\subsection{Double Cell Measurement System}

As shown in Fig. (3), the double cell measurement system comprises two solar cells positioned back-to-back and inclined at an angle of $\delta$. In this study, a voltage ratio (R) of the two solar cells was defined in order to normalize the measurement results. As shown in Fig. (6), the voltage ratio was measured for different inclination angles as the elevation angle, $\theta$, was increased from $0^{\circ}$ to $90^{\circ}$. The results indicate that the ratio drops as the elevation angle, i.e. the solar time angle, increases. Furthermore, it can be seen that the ratio approaches a value of 1 when the time angle is equal to, or

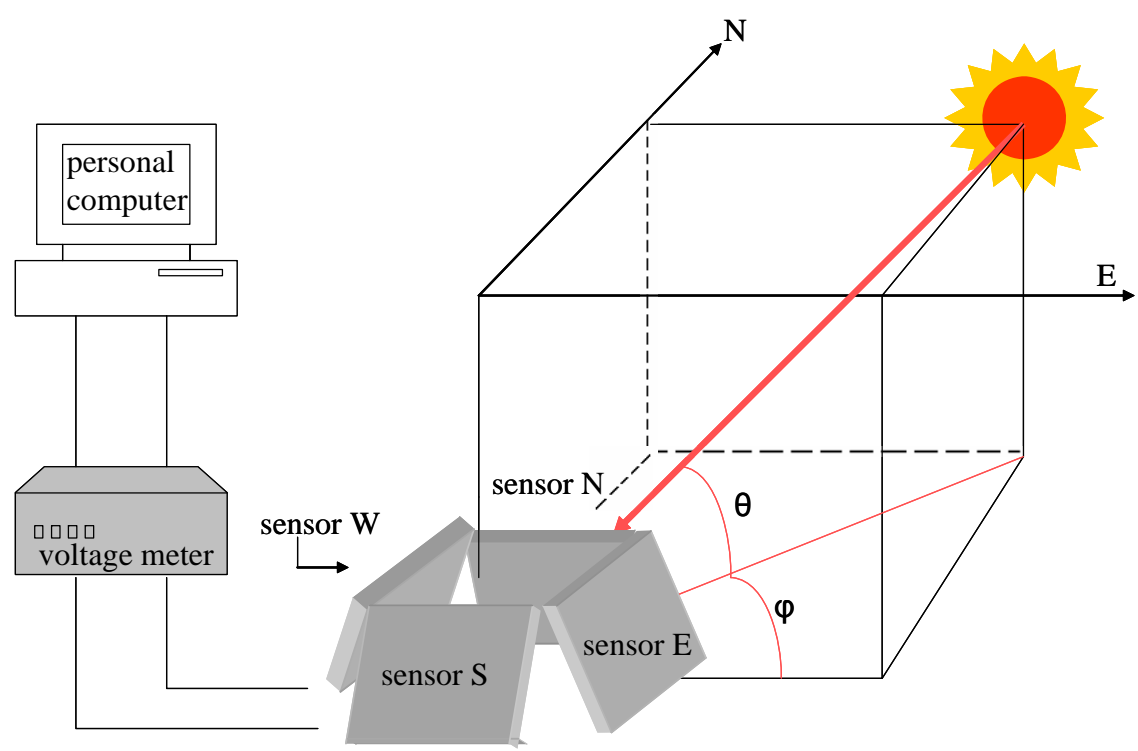

Fig. (4). Schematic representation of quadrantal cell measurement system. 


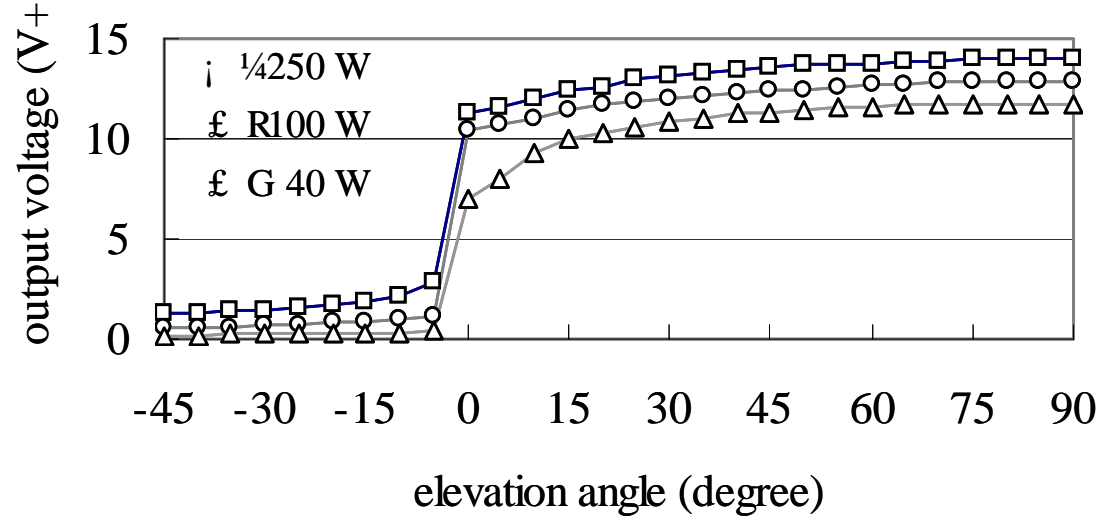

Fig. (5). Output voltages at different elevation angles and illumination powers for single cell measurement system.

greater than, the value of the inclination angle, $\delta$. At an inclination angle of $45^{\circ}$, the maximum range of the measured time angle is observed and the highest sensitivity (i.e. $\Delta \mathrm{R} /$ $\Delta \theta$ : the change of the voltage ratio divided by the change of the time angle) is obtained in Fig. (7) $\left(0.7189 \mathrm{deg}^{-1}\right.$ at time angles $<45^{\circ}$ and $0.0053 \mathrm{deg}^{-1}$ at time angles $>45^{\circ}$ ).

When the time angle is less than the inclination angle, $\delta$, the fitted curve equation for the voltage ratio, $\mathrm{R}$, is expressed by:

$R=-0.0059 \theta^{2}+0.905 \theta+9.9888$ for $\theta<45^{\circ}$

When the time angle is greater than the inclination angle, $\delta$, the fitted curve equation for the voltage ratio, $\mathrm{R}$, is expressed by:

$\mathrm{R}=-0.0053 \theta+1.4587 \quad$ for $\theta>45^{\circ}$

where $\theta$ is the time (elevation) angle $\left({ }^{\circ}\right)$.

Eqs. (1) and (2) provide estimates of the solar time angle at low elevation angles $(<\delta)$ and high elevation angles $(>\delta)$. The double cell measurement system was proven to be a satisfactory system for elevation angle measurement. To measure both the time and latitude angles of the sun, a quadrantal system integrating two double cell systems was developed in the next subsection.

\subsection{Quadrantal Cell Measurement System}

Based on the results obtained above, this study adopted an inclination angle of $45^{\circ}$ and developed the quadrantal cell measurement system shown in Fig. (4). The intention of this

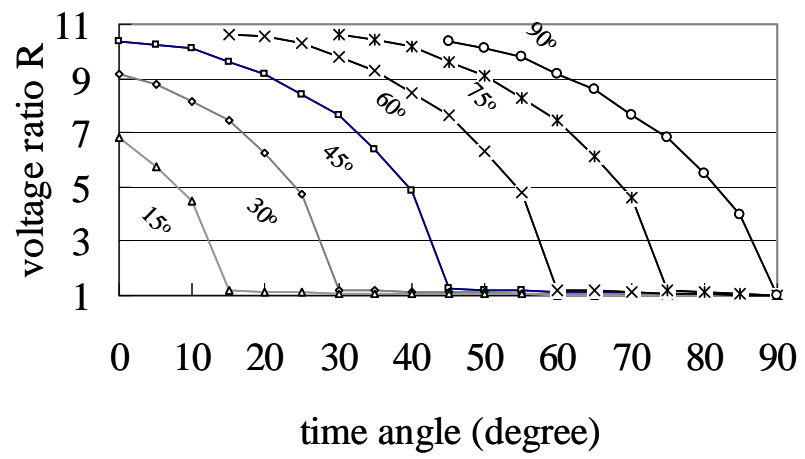

Fig. (6). Ratios of output voltages at different time angles for double cell measurement system of different inclination angles $(\delta=$ $15^{\circ}, 30^{\circ}, 45^{\circ}, 60^{\circ}, 75^{\circ}$ and $90^{\circ}$ ). measurement system was not only to measure the variation in the output voltage caused by changes in the solar time angle (i.e. the elevation angle), but also that caused by changes in the latitude angle of the light source. The corresponding results are shown in Figs. (8) and (9), respectively. Each figure presents both the calibrated (estimated) results against the measured results. The results indicate that the proposed measurement system provides a high degree of correlation with the actual solar orientation. Note that in this configuration, the output voltage ratio $(\mathrm{R})$ of the back-toback sun sensors used to obtain the time angle is derived by dividing the value of Sensor E by that of Sensor W in the morning and by dividing the value of Sensor $\mathrm{W}$ by that of Sensor E in the afternoon. However, the latitude angle of the sun is always calculated by dividing the value of Sensor S by that of Sensor $\mathrm{N}$ regardless of the time of day since the cur-
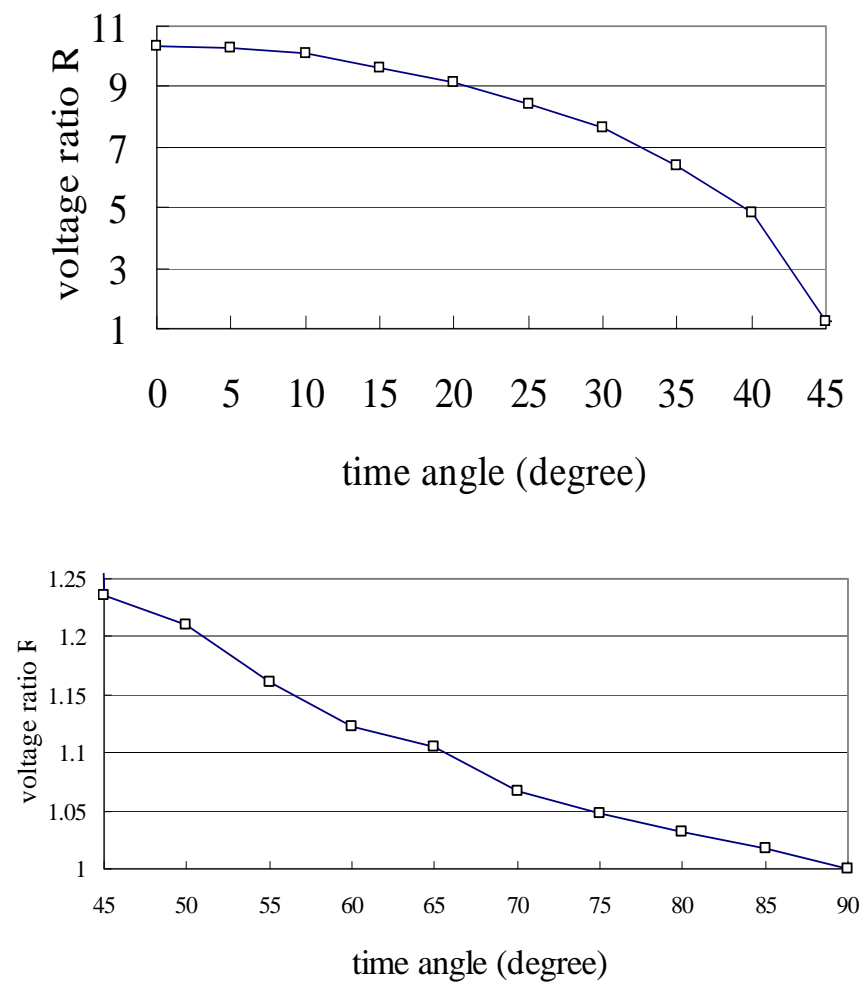

Fig. (7). Ratios of output voltages at different time angles for double cell measurement system $\left(\delta=45^{\circ}\right.$ ): (a) $0^{\circ}-45^{\circ}$, and (b) $45^{\circ}-90^{\circ}$. 


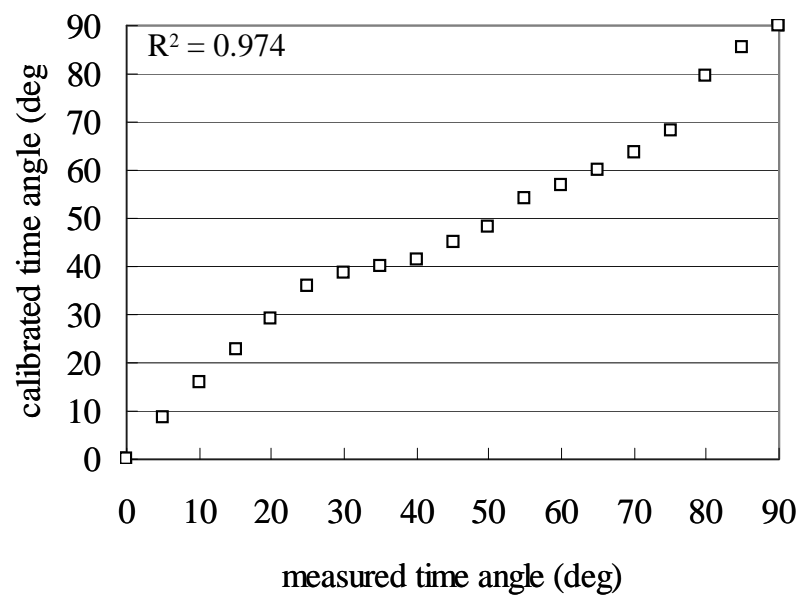

Fig. (8). Correlation between calibrated and measured time angle.

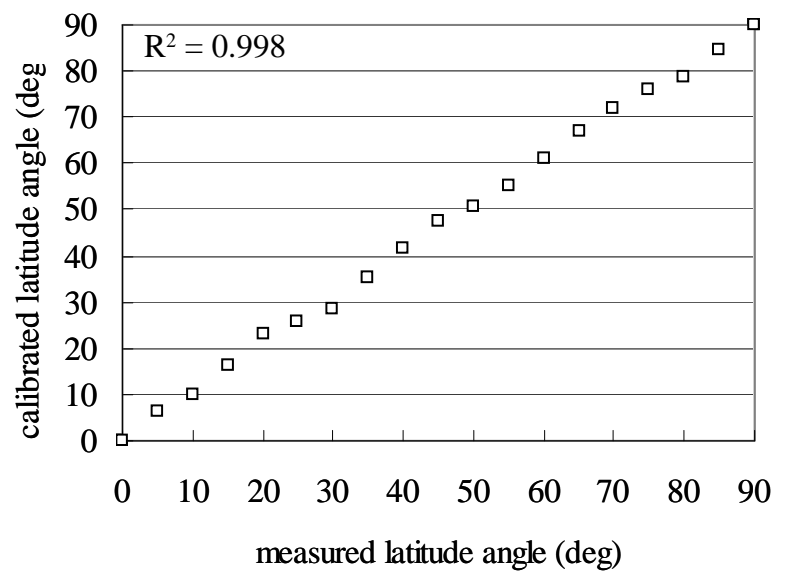

Fig. (9). Correlation between calibrated and measured latitude angle

rent experimental site, i.e. Taiwan, lies north of the Tropic of Cancer, and hence the sun remains to the south in all four seasons.

\section{CONCLUSIONS}

This study has successfully demonstrated a novel solar orientation measurement system with integrated solar cells. A novel assembly configuration and a corresponding geometrical model have been developed for the precise measurement of the time and latitude angles of the sun during daytime hours in all four seasons. It has been shown that inclining two back-to-back sun sensors at an angle of $45^{\circ}$ generates a measurable change in the voltage ratio between the two sensors as the time and latitude angles of the illumination source change. In addition to its precise solar orientation measurement capability and its simplified geometrical model, the proposed device has the further advantage that it can be readily integrated with other solar energy devices.

\section{ACKNOWLEDGEMENT}

The authors would like to thank the financial supports provided by the National Science Council in Taiwan (NSC 95-2221-E-366-017-MY2, NSC 94-2218-E-006-045, NSC 94-2211-E-212-009 and NSC 90-2211-E-006-091) and Ar- chitecture and Building Research Institute, Ministry of the Interior (091301070000G1001, 092301070000G1004, 09430 1070000G1022 and 094301070000G1017).

\section{REFERENCES}

[1] M. B. Muriel, D. C. A. Padilla, T. L. Moratalla and M. L. Coira “Computing the solar vector”, Solar Energy, vol. 70(5), pp. 431-41, 2001.

[2] K. A. Akhmedyarov, B.A. Bazarov, B. Ishankuliev, K.E. Karshenas and G. Schaimerdangulyev, "Economic efficiency of the FV-500 solar photoelectric station with automatic tracking of the sun”, Applied Solar Energy, vol. 22(4), pp. 44-7, 1986.

[3] A. K. Agarwal, "Two axis tracking system for solar concentrators", Renewable Energy, vol. 2(2), pp. 181-2, 1992.

[4] A. M. A. Ibrahim, "The forced circulation performance of a sun tracking parabolic concentrator collector”, in Proceedings of World Renewable Energy Congress, Denver, USA, June 1996.

[5] A. N. Khalifa and S. S. Al-Mutawalli, "Effect of two-axis sun tracking on the performance of compound parabolic concentrators", Energy Conversion and Management, vol. 39(10), pp. 1073-9, 1998.

[6] H. Mohd, M. A. Yakup and A. Q. Malik, "Optimum tilt angle and orientation for solar collector in Brunei Darussalam”, Renewable Energy, vol. 24, pp. 223-34, 2001.

[7] A. H. Algifri and H. A. Al-towaie, "Efficient Orientation Impacts of Box-type Solar Cooker on the Cooker Performance”, Solar Energy, vol. 70, pp. 165-70, 2001.

[8] J. A. Urbano, Y. Matsumoto, R. Asomoza, F. J. Aceves, A. Sotelo and A. Jacome, "5 Wp PV module-based stand-alone solar tracking system”, in Proceedings of $3^{\text {rd }}$ World Conference on Photovoltaic Energy Conversion, Osaka, Japan, May 2003.

[9] M. Berenguel, F. R. Rubio, A. Valverde, P. J. Lara, M. R. Arahal, E. F. Camacho and M. López, "An artificial vision-based control system for automatic heliostat positioning offset correction in a central receiver solar power plant”, Solar Energy, vol. 76, pp. 56375, 2004.

[10] A. Al-Mohamad, "Efficiency improvements of photo-voltaic panels using a sun-tracking system”, Applied Energy, vol. 79(3), pp. 34554, 2004.

[11] A. Kribus, I. Vishnevetsky, M. Meri, A. Yogev and A. Sytnik, "Continuous tracking of heliostats", Journal of Solar Energy Engineering, Transactions of the ASME, vol. 126(3), pp. 842-9, 2004.

[12] S. Abdallah, "The effect of using sun tracking systems on the voltage-current characteristics and power generation of flat plate photovoltaics”, Energy Conversion and Management, vol. 45, pp. 1671-9, 2004.

[13] S. Shanmugan and W. Christraj, "The tracking of the sun for solar paraboloidal dish concentrators”, Journal of Solar Energy Engineering, Transactions of the ASME, vol. 127(1), pp. 156-60, 2005.

[14] S. Kowalski, "Solar Powered Light Fixture”, Renewable Energy, vol. 11, pp. 399, 1997.

[15] R.L. Surman, "5522540 Solar Powered Illuminated Address Number Device and Mailbox Structure”, Solar Energy, vol. 57(3), p. VIII, 1996.

[16] B. Raasakka, “Solar Skylight Apparatus”, Renewable Energy, vol. 12, p. 117,1997

[17] S. Bari, "Optimum Slope Angle and Orientation of Solar Collectors for Different Periods of Possible Utilization”, Energy Conversion \& Management, vol. 41, pp. 855-60, 2000.

[18] T. Tesfamichael and E. Wäckelgård, “Angular Solar Absorptance and Incident Angle Modifier of Selective Absorbers for Solar Thermal Collectors”, Solar Energy, vol. 68, pp. 335-41, 2000.

[19] R. McCluney, "Passive optical solar tracking system", Applied Optics, vol. 22(1), pp. 3433-9, 1983.

[20] R. P. Semma, M. S. Imamura, "Sun tracking controller for multikW photovoltaic concentrator system”, in Photovoltaic Solar Energy Conference; Proceedings of the Third International Conference, Cannes, France, October 27-31, 1980. (A82-24101 10-44) Dordrecht, D. Reidel Publishing Co., 1981, pp. 375-380.

[21] F. M. Al-Naima and N. A. Yaghobian, "Design and construction of a solar tracking system”, Solar and Wind Technology, vol. 7(5), pp. 611-7, 1990. 
[22] A. B. Maish, "Performance of a self-aligning solar array tracking controller", in Proceedings of $21^{\text {st }}$ IEEE Photovoltaic Specialists Conference, Kissimimee, USA, May 1990.

[23] J. H. R. Enslin, "Maximum power point tracking: a cost saving necessity in solar energy systems", Renewable Energy, vol. 2(6), pp. 543-9, 1992.

[24] S. A. Kalogirou, "Design and construction of a one-axis suntracking system”, Solar Energy, vol. 57(6), pp.465-9, 1996.

[25] K. W. Stone and J. P. Sutherland, "Solar two heliostat tracking performance”, in Proceedings of International Solar Energy Conference, Washington DC, USA, Apr. 1997.

[26] J. V. Patil, J. K. Nayak and V. P. Sundersingh, "Design, fabrication and preliminary testing of a two-axes solar tracking system", $R E$ RIC International Energy Journal, vol. 19(1), pp. 15-23, 1997.

[27] C. Hua and C. Shen, "Comparative study of peak power tracking techniques for solar storage system", in Proceedings of $13^{\text {th }}$ Annual Applied Power Electronics and Exposition, Anaheuim, USA, Feb. 1998.

[28] N. H. Helwa, A. B. G. Bahgat, A. M. R. Shafee and E. T. Shenawy, "Maximum collectable solar energy by different solar tracking systems”, Energy Sources, vol. 22(1), pp. 23-34, 2000.

[29] T. Y. Kim, H. G. Ahn, S. K. Park and Y. K. Lee, "A novel maximum power point tracking control for photovoltaic power system under rapidly changing solar radiation”, in Proceedings of IEEE International Symposium on Industrial Electronics, Pusan, Korea, Jun. 2001.

[30] B. D. Belan, D. K. Davydov, V. K. Kovalevski and A. P. Plotnikov, "Automatic tracking system (ATS) for the direct solar radiation intensity", Pribory I Tekhnika Eksperimenta, vol. 1, pp. 159, 2001.

[31] J. Li, W. Lu, X. He and H. Yu, "Mechanical design of an intelligent automatic solar-tracking device”, Acta Energiae Solaris Sinica, vol. 24(3), pp. 330-4, 2003.

[32] W. Jiang and M. Cao, "Emulation sunflower", in Proceedings of $5^{\text {th }}$ International Symposium on Test and Measurement, Shenzhen, China, June 2003.

[33] I. Luque-Heredia, C. Martin, M. T. Mananes, J. M. Moreno, J. L. Auger, V. Bodin, J. Alonso, V. Diazr and G. Sala, "A subdegree precision sun tracker for $1000 \mathrm{X}$ microconcentrator modules", in Proceedings of $3^{\text {rd }}$ World Conference on Photovoltaic Energy Conversion, Osaka, Japan, May 2003.

[34] K. Aiuchi, M. Nakamura, K. Yoshida, Y. Katayama and K. Nakamura, "Sun tracking photo-sensor for solar thermal concentration system", in Proceedings of International Solar Energy Conference, Portland, USA, July 2004.
[35] D. G. Brown and K. W. Stone, "High accuracy/low cost tracking system for solar concentrators using a neural network", in Proceedings of $28^{\text {th }}$ Intersociety Energy Conversion Engineering Conference, Atlanta, USA, Aug. 1993.

[36] H. A. Yousef, "Design and implementation of a fuzzy logic computer-controlled sun tracking system”, in Proceedings of IEEE International Symposium on Industrial Electronics, Bled, Slovenia, Jul. 1999.

[37] M. Alata, M. A. Al-Nimr and Y. Qaroush, "Developing a multipurpose sun tracking system using fuzzy control”, Energy Conversion and Management, vol. 46(7-8), pp. 1229-45, 2005.

[38] D. L. Beshears, G. J. Capps, D. D. Earl, J. K. Jordan, L. C. Maxey, J. D. Muhs and T. M. Leonard, "Tracking systems evaluation for the Hybrid Lighting System”, in Proceedings of International Solar Energy Conference, Kohala Coast, USA, Mar. 2003.

[39] S. Abdallah and S. Nijmeh, "Two axes sun tracking system with PLC control”, Energy Conversion and Management, vol. 45, pp. 1931-9, 2004.

[40] A. Georgiev, P. Roth and A. Olivares, "Sun following system adjustment at the UTFSM", Energy Conversion and Management, vol. 45, pp. 1795-806, 2004.

[41] P. Pradeep, Autonomous, "Low-cost, Automatic Window Covering System for Daylighting Applications”, Renewable Energy, vol. 13, pp. 146, 1998.

[42] J. Wen and T. F. Smith, “Absorption of Solar Energy in a Room”, Solar Energy, vol. 72, pp. 283-97, 2002.

[43] G. Falbel, J. Puig-Suari and A. Peczalski, "Sun Oriented and Powered, 3 Axis and Spin Stabilized Cubesats”, in Proceedings of IEEE Aerospace Conference Proceedings, 2002, pp. 9-16.

[44] Y. M. Chen and H. C. Wu, "Determination of the Solar Cell Panel Installation Angle”, Power Electronics and Drive Systems Proceedings, vol. 2, pp. 549-54, 2001.

[45] V. Badescu, "Different strategies for maximum solar radiation collection on Mars surface”, Acta Astronautica, vol. 43(7-8), pp. 409-21, 1998.

[46] J. Duffie and W. Beckman, Solar Engineering of Thermal Processes, Wiley Interscience, New York, 1991.

[47] W. Lorenz, "Design Guidelines for a Glazing with a Seasonally Dependent Solar Transmittance”, Solar Energy, vol. 63, pp. 79-96, 1998.

[48] W. P. Jr. Schimmel, C.E. Hickox and D.O. Lee, "Tracking and shadowing models for solar collection systems”, American Society of Mechanical Engineers, 77-WA/Sol-8, 8, 1977.

This is an open access article licensed under the terms of the Creative Commons Attribution Non-Commercial License (http://creativecommons.org/licenses/by-nc/3.0/) which permits unrestricted, non-commercial use, distribution and reproduction in any medium, provided the work is properly cited. 